\title{
Preliminary Study of Automobile Lightweight Technology
}

\author{
M.H Li \& Z R Li \\ Shenyang Institute of Technology, Fushun China \\ L Jiang \\ Heilongjiang Institute of Technology, Harbin, China
}

\begin{abstract}
Energy saving, environmental protection, safety is the main focus of the topic in today's world automobile industry, the automobile lightweight technology is an important way to achieve this goal. This paper takes the automobile lightweight technology as the research object, it studies the automobile lightweight technology respectively through the automobile body materials, processing technology of the engine cylinder block, and automobile running material optimization, the comprehensive application automobile lightweight technology provides the reference for the future.
\end{abstract}

KEYWORD: Lightweight; Automobile; Alloy material; Thermal spraying.

\section{THE INTRODUCTION}

In recent years, with the rapid development of automobile industry, it brings great convenience to people's travel, at the same time, it also appears energy shortage and serious pollution problems (Bobzin K, 2008). How to reduce energy consumption of the vehicle, reduce pollution to the environment has become thorny issues of the automotive industry concern (Cai Qigang, 2009). From steam cars to now, a variety of hybrid and electric vehicles, the development of automobile has experienced great changes. Not only the appearance of the automobile, the internal structure and manufacturing material has changed, and even the block of the engine cylinder material has changed significantly .To ensure that the car is under the premise of quality and safety, in addition to improve the car engine performance, improve the utilization rate of the fuel, and reduce emissions to meet the requirements of environmental protection, also can reduce weight of the car to save fuel, achieve energy conservation and environmental protection. In order to reduce car weight, we can choose aluminum, magnesium alloy material to finish automobile parts (Dang Chunmei et al, 2011) (Li Zengrong et al, 2011). World aluminum association research report pointed out: car 10 litres per consumption, including 6 litres of consumption in car weight, if a car's weight of each reduce $10 \%$, the fuel consumption could be as reduced about $12 \%$ ( $\mathrm{Li}$ Yanping. 2007) (LIU Z, 2000) (Qi J L, 2013) (Qian R Y. 2006). As the density of aluminum alloy is small, easy to machining, high corrosion resistance is strong, repeated utilization, etc. and therefore is widely applied to various industries, especially in automobile industry (Sampson E R. 1998) (Sun Z G, 2014).

\section{THE DEVELOPMENT TREND OF AUTOMOBILE BODY LIGHTWEIGHT}

The car body structure as shown in figure 1, mainly consists of the main frame and many covering parts. Car body lightweight mainly includes two aspects: on the one hand is the body structure optimization design, in order to reduce overall body weight; On the other hand, by reducing the weight of the car body structure to achieve the lightweight. Automobile lightweight body material usage is also put forward higher request, on the premise of ensuring strength and stiffness of the automobile parts material, makes the weight of the parts is lighter, is an effective way of lightweight automobile body. The use of aluminum, magnesium alloy and high strength plastic, gets a better solution to this problem, at the same time, it is widely used in the world automobile industry (Vencl A et al, 2009) (Wang M, 2008) (Wen S Z. 2008). Table 1 is in recent years, the composition of materials used in car manufacturing process. 


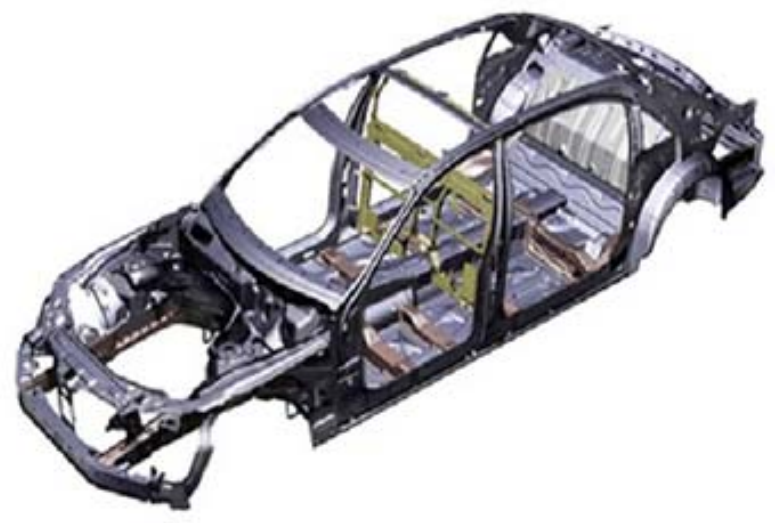

Fig.1 Structure of car body

From the change of these statistics in table 1 shows, steel and non-ferrous metals is the main material of automobile production, but the total weight of automobile is constantly reduced, automobile material is changing, the main characteristic is heavy materials such as steel is constantly reduced, the proportion is also on the decrease such as aluminum and magnesium in light alloy is increasing, In the past ten years, it increased by $75 \mathrm{~kg}$, and the proportion increased by $6.7 \%$ in this decade, material experts had predicted that in the next ten years or even longer period of time, a large number of light metal such as aluminum, magnesium, replace iron and steel materials for car production, so that making cars into half the weight.

With the rapid development of aluminum, magnesium alloy smelting technology, more and more aluminum, magnesium alloy material will be selected to automotive components, such as car radiator, hood and trunk lid is produced by aluminium alloy, in the near future, automobile fuel tanks and bumper will also be made of aluminum, magnesium alloy instead of steel plate to manufacture, Europe and the United States and other countries have adopted of aluminum, magnesium alloy on the limousine to manufacture these parts.

Table 1 The composition of automobile material

\begin{tabular}{c|c|c|c|c|c|c|c|c}
\hline years & \multicolumn{2}{|c|}{ In 2000 } & \multicolumn{2}{c}{ In 2005 } & \multicolumn{2}{c}{ In 2010 } & \multicolumn{2}{c}{ In 2015 } \\
\hline material & $\begin{array}{c}\text { Weight } \\
(\mathrm{kg})\end{array}$ & $\begin{array}{c}\text { proportion } \\
(\%)\end{array}$ & $\begin{array}{c}\text { Weight } \\
(\mathrm{kg})\end{array}$ & $\begin{array}{c}\text { proportion } \\
(\%)\end{array}$ & $\begin{array}{c}\text { Weight } \\
(\mathrm{kg})\end{array}$ & $\begin{array}{c}\text { proportion } \\
(\%)\end{array}$ & $\begin{array}{c}\text { Weigh } \\
(\mathrm{kg})\end{array}$ & $\begin{array}{c}\text { proportion } \\
(\%)\end{array}$ \\
\hline steel & 780 & 51.6 & 705 & 49 & 600 & 45.3 & 540 & 41.1 \\
\hline cast iron & 205 & 13.6 & 186 & 12.9 & 132 & 10 & 113 & 8.6 \\
\hline $\begin{array}{c}\text { aluminum, } \\
\text { magnesium }\end{array}$ & 105 & 6.9 & 131 & 9.1 & 180 & 13.6 & 201 \\
\hline plastic & 151 & 10 & 163 & 11.4 & 172 & 12.9 & 199 & 15 \\
\hline other & 217 & 17.9 & 253 & 17.6 & 241 & 18.2 & 262 & 20 \\
\hline total & 1512 & 100 & 1438 & 100 & 1325 & 100 & 1315 & 100 \\
\hline
\end{tabular}

With the rapid development of materials science and technology, in recent years, in Europe and the United States and other developed countries, carbon fiber has been successfully used in the production of limousines. Carbon fiber is a new type of material, the beginning is mainly used in military, aerospace and other high-tech fields, its mechanical property is very excellent, the proportion is less than a quarter of the steel, but the tensile strength is 7 times more than that of steel degrees, the car body, roof, brake discs and other parts are made of carbon fiber will reduce the weight of the car sharply, less fuel consumption. Although the cost of carbon fiber is higher, but with the constant development and expansion of carbon fiber industry, and to meet the requirements of energy conservation and emissions reduction and automobile lightweight, the cost of carbon fiber will decline, it will get more and more used in the development of the future car.

\section{CAR ENGINE LIGHTWEIGHT METHODS}

As known, the engine in the automobile is the monomer weight larger parts. According to the research, at present, more than sixty percent of the engine in the world adopt aluminum alloy to make (Dang Chunmei et al, 2011). Although aluminum alloy engine can make automobile reduced weight, reduce the energy consumption of the automobile, but, there is a fatal weakness of aluminum alloy cylinder block, it can't meet the requirement of the wear resistance of cylinder body. In order to solve this problem, scientific researchers through unremitting efforts, and find out the three ways to solve this problem. Method one: embedded in the aluminum alloy cylinder with high wear resistance of cast iron cylinder liner. As shown in fig.2. 


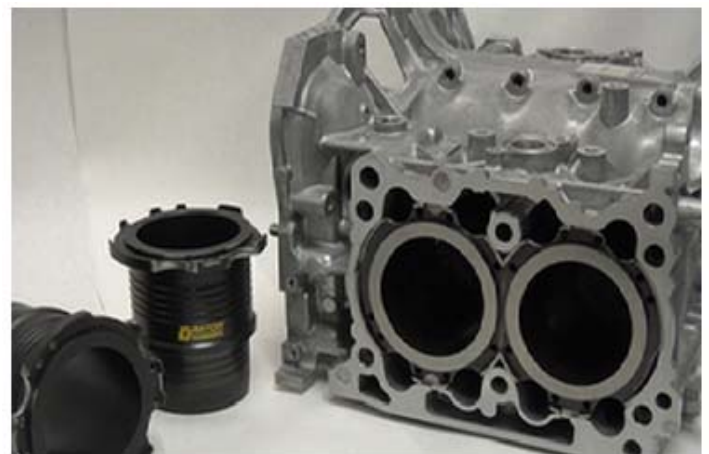

Fig.2 Cast iron cylinder liner and aluminum cylinder block

Method 2: use of special aluminum alloy casts the cylinder block with high wear resistance; Method 3: use of spraying high wear resistance of coating in the cylinder wall of aluminum alloy material. As shown in fig.3.

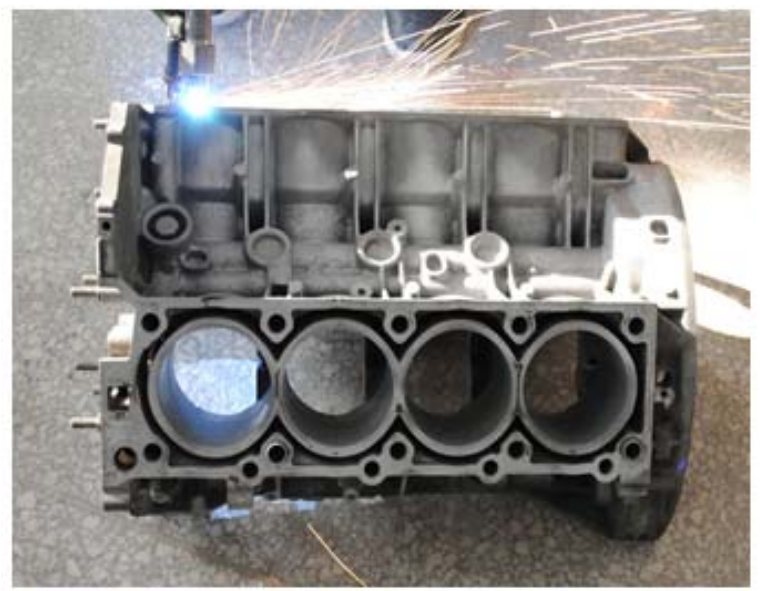

Fig.3 Aluminum cylinder wall coating

Before spraying, the inner wall of cylinder body is coarsening processed, as shown in figure 4, the main purpose of coarsening is to enhance the intensity of the combination of coating and lining, the oil, and grease and other must clean up by means of chemical reagents before the surface coarsening, so it can increase the adhesion of coating and the magnesium substrate.

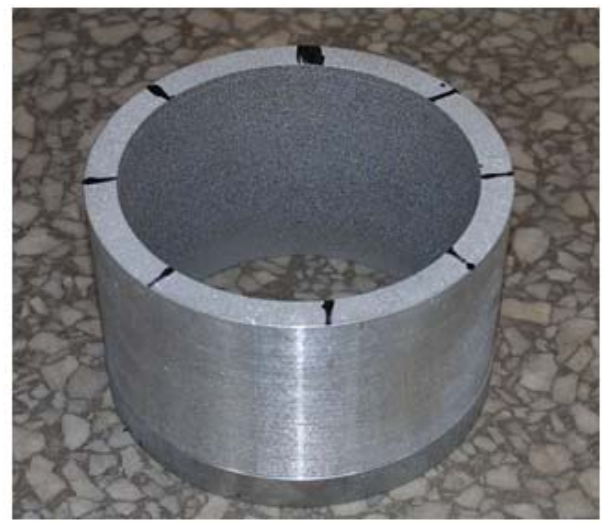

Fig.4 The lining surface coarsening
Although the first method meet the requirements of procession of cylinder wear resistance with the need of assembly, can make the overall size of the aluminum alloy cylinder increased, In addition, due to the difference of heat transfer and the expansion rate between the two is serious, it shorten the service life of cylinder block ; The second method may seem simple, but actually has a lot of problems, for example, the flexible component can't change, combined with the friction pair of piston parts is difficult to form best (Li Zengrong et al, 2011). But the third method for preparation of engine cylinder body can avoid the shortcomings above, first of all, using thermal spray technology, can spray some kind of iron base alloy coating in the wall of aluminum alloy cylinder block, in the case of not change the cylinder body weight basically to meet the requirement of wear-resistant cylinder body, in addition, the ratio of coating material components can be flexible; and the coating on the inner wall of the cylinder block is completed, there will be no problem such as assembly clearance and heat transfer issue is poor. therefore, using this method to make the engine block, it provide a powerful guarantee for the realization of the lightweight car, some countries, such as Europe and the United States have already researched and developed high-end car ,it started to use this method to make the engine cylinder block, in our country, it is still in the laboratory research stage.

\section{HE DEVELOPMENT TREND OF CARS RUNNING MATERIAL EFFICIENCY}

\subsection{Use a high calorific value of fuel}

High calorific value of fuel, it is an effective way to realize automobile lightweight, in order to realize the automobile industry's ambitious goal of pursuing efficient environmental protection, on the one hand, to reduce the weight of car, on the one hand, also wants to promote the quality of the automobile run material, how to improve the existing fuel combustion heat value is also one of the effective ways to achieve this grand blueprint. At present, the main fuel of vehicles use is gasoline, an increasing tense in oil resources, under the action of increasing environmental pollution, explore and seek alternative vehicle fuel has become an urgent problem. For example, use compressed or liquefied natural gas (LNG) and compressed or liquefied hydrogen as a motor fuel.

\subsection{Adopt efficient clean energy}

Adopt efficient clean energy, is also an effective way to realize car lightweight. The world's automobile industry through constantly exploring, developed a petrol-electric hybrid cars, compared with the same size cars, fuel cost reduced a lot. Although hybrid sedan 
has great advantage in energy conservation and emissions reduction, but due to the current cost is higher, there are some technical deficiencies, so it can't be mass production, so there's no true sense into the market, but many insiders said the industrialization prospect of the automobile is better, how to breakthrough in technology, combined with the government's subsidy policy guidance, it is estimated that there will be a big difference after five years.

\subsection{Improve the working efficiency of the engine}

Turbo technology can make the engine increase the output power under the condition of invariable in work efficiency, one of the earliest turbo technology is applied to sports car or formula, so that in the racing of engine emissions limits, the engine will be able to get more power. Fig.5 is Honda released turbocharged engine. Turbocharging unit is actually a kind of air compressors, compressed air is to increase the engine air inflow, in general, a turbocharging makes use of inertial force of engine exhaust to drive the turbine, turbine drives the coaxial impeller, the impeller compressed the air that from filter pipe, pressurized into the cylinder.

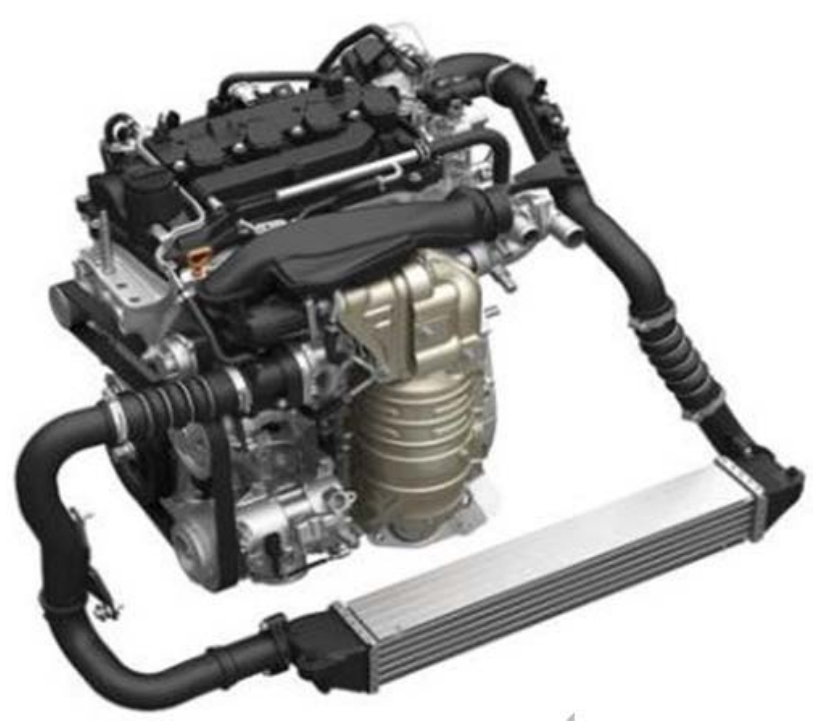

Fig.5 Turbocharges engine

When the engine speed is accelerated, emission speed and turbine speed synchronous speed up, the impeller compressed more air into the cylinder, the increase of air pressure and density can burn more fuel, a corresponding increase in fuel quantity and adjust the speed of the engine, can increase the engine's power output, the engine is rely on fuel combustion in cylinder work to generate power, because the input amount of fuel is limited by the amount of inhaled air in the cylinder, the power produced by the engine will be limited, If the running performance of engine is in the best state, increase the output power can only compress more air into the cylinder to increase the amount of fuel, thus improve the combustion work ability. So under the condition of current technology, install the machinery of turbocharger can increase the output power. The turbocharger is actually an air compressor. It makes use of the exhaust gases from the engine as power to drive the turbine (located in the exhaust passage), turbine drives the coaxial impeller, the impeller compresses the fresh air sent by air filter pipe and then into the cylinder. When the engine speed is accelerated, emission speed and turbine speed synchronous speed up, air compression degree is increased, and the volume of engine increases correspondingly, can increase the output power of the engine. the biggest advantage of turbo charging is that can increase engine power and torque without any increase in engine displacement, on the basis of an engine fitted with a turbocharger, its maximum power output compared to not install the turbocharger, can increase about $40 \%$ or more, so as to realize energy conservation and emissions reduction.

\section{CONCLUSION}

Automobile's lightweight is an inevitable trend for the future development of automobile industry, is also a huge system engineering, it needs a lot of science and technology personnel's unremitting efforts. Lightweight includes all aspects of the car, the car body and parts is made of lightweight material, at the same time, the development of various new type alloy material is also the direction of scientific research personnel effort. In addition, the research and development of hydrogen fuel car and speed up the development petrol-electric hybrid car, is also an effective way to realize the automobile lightweight.

\section{REFERENCES}

Bobzin K, 2008, Thermal spraying of cylinder bores with the plasma transferred wire arc process Surface and Coatings Technology, 202(6): 4438-4443.

Cai Qigang, 2009 Aluminum alloy on the car body application status and the discussion of development trend. Guangxi light industry, 25(1):28-29.

Dang Chunmei, Xie Weidong. 2011, The application of aluminum, magnesium alloy material in automobile industry. The hot working processes, 42(4):1-4.

LIU Z, 2000, Effect of Surface Treatment on Properties of Carbon Fiber and Reinforced Composites. Chinese Journal of Materials Research, 14(5):16-18.

Li Yanping. 2007, The application of aluminum alloy in automotive industry and prospect. Aluminum processing, 58(1):23-24.

Li Zengrong, Wu Bi. 2011, Thermal spraying technology in the application of lightweight car engine cylinder. Science and technology innovation and application, 108(22):21-23.

Qian R Y. 2006, Linghtweight technology of car engine, Automobile .Technology \& Material, 6(6):1-4+10. 
Qi J L, 2013, In-situ synthesis of CNTs reinforced Ti based brazing powder by PECVD. China Welding, 22(4):42-46.

Sampson E R. 1998, Cored wire application using electric arc spray. Proceedings of ITSC, France, 42(5):133-137.

Sun Z G, 2014, Weld seam recognition algorithm based on HSI space for pipeline ultrasonic flaw inspection. China Welding, 23(3):16-20.

Vencl A, Mrdak M, Banjac M. 2009, Correlation of microstructures and tribological properties of ferrous coatings deposited by atmospheric plasma spraying on Al-Si cast alloy substrate , Metallurgical and Materials Transactions: A, 40(2): 398-405.

Wang M, 2008, Numerical simulation of temperature fields for T-joint during TIG welding of titanium alloy. China welding, 17(3):6-9.

Wen S Z. 2008, Research progress on wear of materials, Tribology, 28(1):1-5. 